\title{
Indifferent reporting of notifiable diseases
}

$\mathrm{I}$ $\mathrm{t}$ is a truism that Canadian physicians and other health workers are legally compelled to report cases of specified communicable diseases and infections. In some provinces, the list tops 110 diseases, while in others, it's as low as 60 .

It also appears to be a fact that most physicians are about as irregular with respect to that legal obligation as senators are in attending the red chamber. But regulators appear equally disinclined to prosecute for failure to report and the end result, experts say, is an incomplete picture of the incidence of communicable diseases in Canada and a muddled understanding of the notion of mandatory reporting.

Communicable disease reporting in Canada falls within the constitutional no man's land that typifies matters of health care, so what has emerged is a quintessentially haphazard and piecemeal system, although the reporting of infectious diseases is absolutely vital to the detection and control of outbreaks.

Needless to say, the variations can lead to considerable hand-wringing, like that which recently occurred in Nova Scotia when the province made reporting of Clostridium difficile infections mandatory (http://gov.ns.ca/news/details .asp?id=20120402004).

As a signatory to the International Health Regulations (IHR), Canada has an obligation to report incidences of three diseases: yellow fever, plague and cholera (www.who.int/csr/resources/publications /introduction/en/index $4 . h$ tml). The revised 2005 regulations also place an onus on Canada and other signatories to report all diseases that might be considered to potentially cause a "public health emergency of international concern," using an algorithm of "four criteria: (1) the seriousness of the public health impact; (2) the unusual or unexpected nature of the event; (3) the potential for international spread; and (4) the risk of restrictions on international travel or trade."

Essentially, that creates a situation

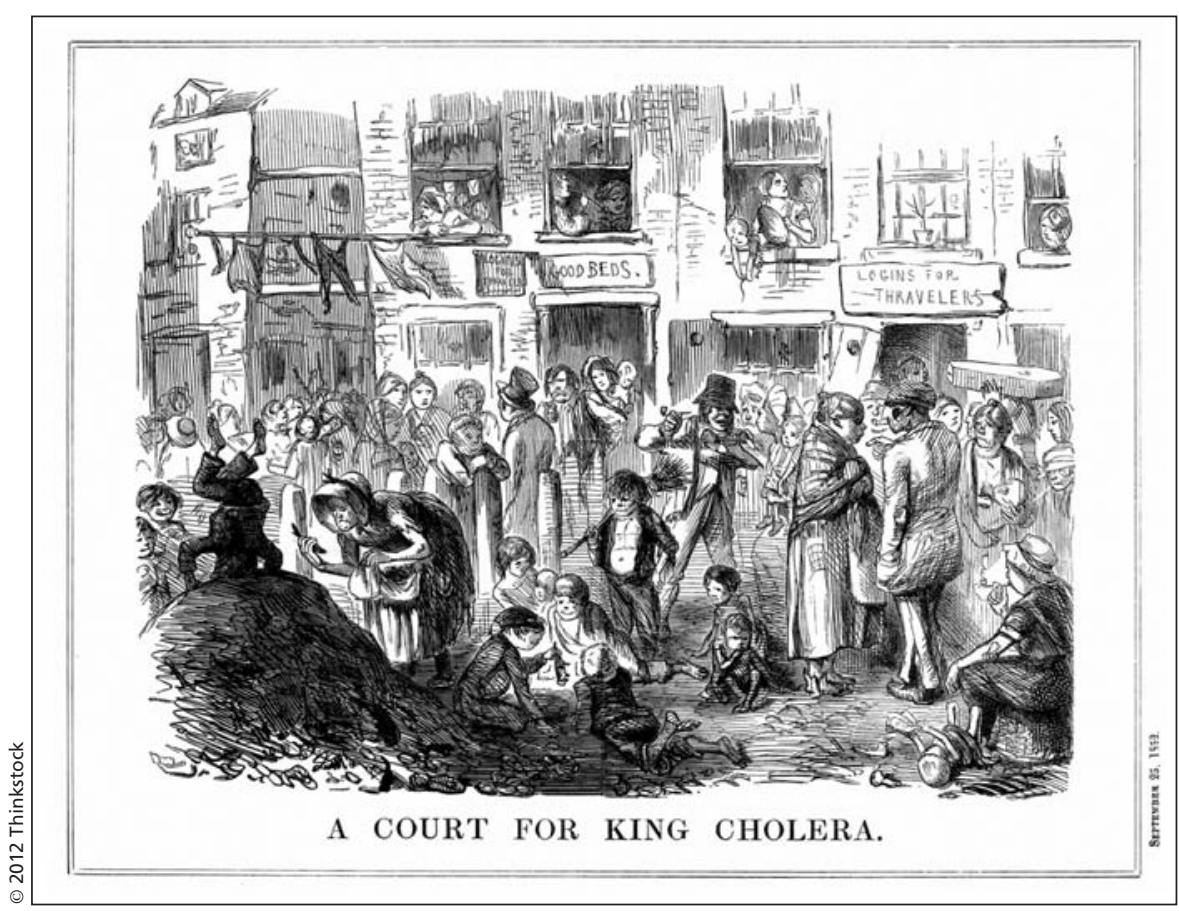

As a signatory to the International Health Regulations, Canada has an obligation to report cases of yellow fever, plague, cholera and all other diseases that might be considered to potentially cause a "public health emergency of international concern."

where every country makes its own determination of what diseases are internationally notifiable (aside from yellow fever, plague and cholera). In Canada's case, it appears there are a total of 12 such diseases, which the Public Health Agency of Canada (PHAC) has defined as being: anthrax, botulism, cholera, new sub-types of influenza, invasive meningococcal disease, pneumonic plague, poliomyelitis, SARS, smallpox, tularemia, viral hemorrhagic fevers and yellow fever (www .phac-aspc.gc.ca/publicat/ccdr-rmtc/06vol 32/dr3219a-eng.php).

Because of the Canadian jurisdictional quaqmire, those diseases are not, however, ones that are federally mandated as notifiable. While the federal government has the authority, under such laws as the Quarantine Act, to theoretically impose a national requirement, it has chosen not to do so, preferring instead to craft, in conjunction with the provinces, a "consensus" list of roughly 50 nonmandatory "nationally notifiable diseases" (http://dsol-smed .phac-aspc.gc.ca/dsol-smed/ndis/list-eng .php). Mandatory requirements are left to the provinces, typically under the rubric of regulatory authority for public health.

It's led to a highly checkerboard situation with respect to reporting requirements. There are diseases such as Lyme disease, psittacosis, Q fever and Yersinia that make every provincial list. But there are others which are reportable only in a single province, such as babesiosis (Quebec), dysentery (Newfoundland and Labrador) and Guillain-Barré syndrome (New Brunswick). Moreover, some provincial lists are a trifle ambiguous, as several jurisdictions have blanket legislative provisions that compel health care workers to report an "unusual" illness or "novel" organism.

But provincial officials say the variations are largely a function of regional disease outbreaks or incidence rates.

For some diseases, a rare case is "not a big deal" and it's only those for which there is a potential for a major outbreak that are placed on the lists, 
says Dr. Martin Lavoie, Alberta's deputy chief medical officer of health.

Moreover, the provinces have moved in tandem when there's been a perceived public health threat, such as last decade's SARS outbreak and anthrax scares, notes Dr. Bonnie Henry, British Columbia's medical director for communicable disease prevention.

But there are other diseases that BC doesn't believe should be reportable, she adds. For example, "here in BC, chickenpox has never been a reportable disease. We don't collect that information for a variety of reasons. One was it was very poorly reported - it's a clinical diagnosis that most physicians make and they don't report it to public health - and there's no public health follow up that we would do with a case of chickenpox."

Overall, it's a system that works, Sylwia Gomes, a spokesperson for PHAC, writes in an email. "Although notification to the federal level is voluntary, it has been done since 1924, which demonstrates a long precedent and acknowledgement as a valued activity by all parties."

Assuming, of course, that all those required to report communicable diseases in fact did so. But compliance is suboptimal, as many a study has shown, along with reports such as one from PHAC, Suboptimal reporting of notifiable diseases in Canadian emergency departments: A survey of emergency physician knowledge, practices, and perceived barriers (www.phac-aspc.gc .ca/publicat/ccdr-rmtc/06vol32/dr3217a -eng.php).

"Physician compliance with respect to mandatory reporting of common notifiable diseases has reportedly varied between 6\% and 90\%," the PHAC study noted. "Failure in mandatory public health reporting by physicians has been attributed to lack of knowledge regarding the components of notification, including the requirement to report, which diseases are reportable, and how or to whom to report. Poor compliance has also been attributed to physician assumption that someone else will report, concerns regarding the effort required for reporting, insufficient compensation for doing so, and a view that no useful action is taken on notifications. Physicians cite poor accessibility and complexity of notification forms, lack of motivation secondary to poor feedback, and a perception that reporting these diseases is a useless endeavor."

Nevertheless, most provinces do specify some form of penalty for failure to report a communicable disease. BC's legislation appears the stiffest, with the penalty specified in the province's Health Act for failure to report set at a fine of up to $\$ 200000$ or 12 months in jail, or both. Other provinces, such as Manitoba, Nova Scotia and New Brunswick, do not appear to impose penalties. Most provinces impose fairly modest penalties, such as the $\$ 100$ fine specified in Newfoundland and Labrador's legislation or the fines of between $\$ 600-\$ 1200$ in Quebec. Ontario's Health Protection and Promotion Act indicates that physicians or nurses who do not report communicable diseases are liable to fines of "not more than $\$ 5,000$ for every day or part of a day on which the offence occurs or continues."

The specified penalties, however, are somewhat moot, if only because there does not appear to have been an instance in which a physician or health care professional was charged for failure to report a communicable disease. Neither the Royal College of Physicians and Surgeons of Canada nor the Canadian Medical Protective Association say they're aware of any instance in which a Canadian physician has been charged with failure to report a communicable disease.

Meanwhile, PHAC declined comment on whether it has heard of anyone having been charged. "The provinces and territories are primarily responsible for the both health care service delivery and public health within their respective jurisdictions. This responsibility also includes the development and enforcement of legislation related to health care and public health (e.g. legally notifiable diseases)," Jirina Vilk, spokeswoman for PHAC, wrote in an email.
But the variations in provincial reporting requirements, and the differing levels of zeal with which diseases are reported, has a major consequence in the form of inaccuracies in the provincial and national disease incidence reports.

"One of the major difficulties is to get physicians or nurses or directors of medical facilities or others to report to public health," Lavoie says. "So we know we have significant underreporting" particularly with respect to diseases that are difficult to identify or are viewed as insignificant by health care workers.

Henry says most BC physicians are altogether willing to report high-profile diseases but inclined to overlook more common ones. "We've done some work out here with Lyme disease in $\mathrm{BC}$ and we find that physicians are quite comfortable diagnosing and treating someone, but they don't think about reporting," she says.

As a rule, diseases that require confirmation through laboratory testing are reported more frequently, as it's easy for a lab to send along findings to a local health authority, Lavoie and Henry add.

A fairly accurate gauge of the incidence of reportable diseases is essential to determining whether to "enhance" testing, says Dr. Saqib Shahab, deputy chief medical health officer for Saskatchewan. For example, he notes, pertussis surveillance measures among adults within the province were elevated after health workers noticed rising rates among infants.

Similarly, a rising incidence of measles in 2011 prompted warnings to physicians to undertake measles tests for all children who presented with a rash or fever, Shahab adds. "We don't want to over-test people when it's not really that useful. But if there's a signal of concern, that's usually when we work with our healthcare provider partners and the labs to just increase testing for a while and then we can settle down for a bit." - Andrea Hill, Ottawa, Ont.

CMAJ 2012. DOI:10.1503/cmaj.109-4193 